\title{
The capacity analysis of wide flange steel section as beam- column elements
}

\author{
Mukhlis Islam $^{1 *}$, Ade Sri Wahyuni ${ }^{1}$, and Jeirry Anggara ${ }^{1}$ \\ ${ }^{1}$ Civil Engineering Department, Faculty of Engineering, University of Bengkulu. WR. Supratman Rd., Bengkulu 38371
}

\begin{abstract}
The design of the steel frame structure for beam, column, and beam-column elements usually takes several iterations to obtain optimum results that are safe, efficient, and economical. The problems that arise due to the number of iteration for the design process are the basis for this research. The research was conducted on 100 sections IWF and HCS which are consisted of 81 sections of IWF and 19 sections of HCS. The analysis was carried out regarding SNI 1729:2015. The results of this study are in the form of moment capacity graphs and tables of the axial capacity of steel sections as well as coefficients of $m$ and $U$ for beam-column design. Moment capacity graphs and tables of the axial capacity of IWF and HCS profiles produced could be used to reduce the number of iteration in designing safe and efficient steel profiles as beam, column, and beam-column elements. Analysis results show that the usage of the graphs and tables for the beam-column design process will reduce the number of iteration needed.
\end{abstract}

\section{Introduction}

Along with the development of technology in the field of construction, steel sections have become one of the options to be used as structural elements in building construction. This steel construction can be seen in today's buildings such as houses, factories, stadiums, hotels, and even other high-rise buildings [1].

There are various types and sizes of steel sections available in Indonesia, such as WF (Wide Flange) and HCS (Heavy Column Section). The WF section consists of I and $\mathrm{H}$ beam sections, wherein total there are 81 steel sections with different dimensions. The HCS section consists of 19 sections with different dimensions [2].

Various sections available on the market with different specifications make engineers carry out repeated iteration to obtain a section that is safe, efficient, and economical. The repeated iterations carried out by the engineers made the structural design process would be tedious and required a lot of effort to get an efficient steel section.

The results of this study will be design aids in the form of tables of axial capacity and nominal moments of IWF and HCS sections. These tools are then used in designing steel structures that are safe, efficient, and economical. By using this tool, there will be fewer experiments, so it doesn't take up much time and effort.

\section{Literature Review}

\footnotetext{
* Corresponding Author: islam.mukhlis@unib.ac.id
}

\subsection{Steel Section}

Steel material first appeared in the 19th century where steel is an alloy of iron and carbon. The carbon material found in steel is less than the carbon material in cast iron. The manufacture of large volume steel was first carried out by Sir Henry Bessemer, who received a patent from the British government for his findings in 1855 [1].

The first steel frame structure was the Home Insurance Company Building in Chicago [1].

\subsection{Beam}

Beams according to SNI 1729-2015 are nominal horizontal structural members that have the main function to withstand bending moments [3].

Beams are structural components that carry gravity loads, such as dead loads and live loads, beam structural components are a combination of compression elements and tensile elements [1].

\subsection{Column}

Columns according to SNI 1729-2015 are nominal vertical structural members that have the main function of resisting axial compression forces.

Compressive members are intended for structural members that carry centric compressive loads right at the center of gravity of the cross-section or column with only axial forces [4]. 


\subsection{Beam-Column}

Beams-columns according to SNI 1729-2015 are structural components that resist axial forces and bending moments.

Structural members sometimes the effects of the combination of axial forces and bending moments are not negligible, hence the combination of axial forces and bending moments must be considered in the design process of structural members. These structural members are often referred to as beam-column elements [1].

\section{Research Methodology}

The research was conducted by analyzing the crosssectional capacity of IWF and HCS steel sections as a beam, column, and beam-column elements. This research is applied to academic research and is carried out carefully, systematically, and continuously on each IWF and HCS (heavy column section) steel profile used for structural design purposes.

The data used in the analysis process are IWF and HCS sections which consist of 81 IWF types and 19 HCS types.

\subsection{Section Capacity Calculation procedure}

Calculations were made for the sections of compact web and compact flange, compact web of the non-compact flange, and compact web and slender flange for beam elements, while for column elements only non-slender sections were analyzed. The steps for calculating the section's capacity are carried out with the following procedure:

\subsubsection{Calculate Additional Data for Setion Capacity Calculation}

a. Radius of gyration (axis-x dan axis-y)

$$
\begin{aligned}
& r x=\sqrt{\frac{I_{x}}{A}} \\
& r x=\sqrt{\frac{I_{y}}{A}}
\end{aligned}
$$

b. Plastic section modulus (axis- $x$ dan axis-y)

$$
\begin{aligned}
& Z x=b \cdot t f .(d-t f)+1 / 4 t w(d-2 t f)^{2}(3) \\
& Z y=1 / 2 \quad b^{2} \cdot t f+1 / 4 t w^{2}(d-2 t f)
\end{aligned}
$$

c. Warping torsion constants

$$
J=\frac{1}{3}\left(2 \cdot b \cdot t f^{3}+d^{\prime} \cdot t w^{3}\right)
$$

$d^{\prime}$ is obtained by calculation of:

$$
d^{\prime}=h-t f
$$

\subsubsection{Column Action Calculation}

The procedure is as follows:

a. Controlling of slenderness ratio of web and flange of the sections to control the effect of local buckling.

b. Calculating the critical stress of the section $\left(F_{c r}\right)$

c. Calculating the axial capacity of the column

\subsubsection{Beam Action Calculation}

a. Controlling the slenderness ratio of web and flange of the sections to the effect of local buckling

b. Calculating the nominal capacity of bending moment based on lateral-torsional buckling criteria

a) Section with compact web and compact flanges bending about its major axis, with categories of:

- $\quad L_{b}<L_{p}$, short span beam

- $L_{p}<L_{b}<L_{r}$, medium span beam

- $L_{b}>L_{r}$, long-span beam

b) Section with compact web and non-compact flange bending about its major axis.

Beam-column analysis was carried out on three types of effective length factor $(\mathrm{k})$. The three effective length factors consist of:

1. $\mathrm{k}=1$, nominal moment capacity of the beam at span $\mathrm{L}$ compared to axial capacity at $\mathrm{kL}=\mathrm{L}$.

2. $\mathrm{k}=0,5$, nominal moment capacity of the beam at span $\mathrm{L}$ compared to axial capacity at $\mathrm{kL}=0,5 \mathrm{~L}$.

3. $\mathrm{k}=2$, nominal moment capacity of the beam at span $\mathrm{L}$ compared to axial capacity at $\mathrm{kL}=2 \mathrm{~L}$.

\subsubsection{Plotting of Nominal Bending Capacity Graphs of Beams}

The nominal moment capacity graphs of the beam are formed from the relationship between the length of the unfettered beam $\left(L_{b}\right)$ and the nominal moment capacity of the beam $\left(\varnothing M_{n}\right)$. The nominal moment capacity curve of the beam is drawn according to the mechanical properties of the steel, namely A36, A529 Gr. 50, A572 Gr. 42, A572 Gr. 50, A572 Gr. 55, A 572 Gr. 60, A572 Gr. 65, and A 91370 . The length of the curved line is limited to 30 meters. However, if the $2 \mathrm{Lr}$ value of the profile is less than $30(2 \mathrm{Lr}<30)$, then the length of the curve is only drawn until the curve is at the $2 \mathrm{Lr}$ point and if the length of the $2 \mathrm{Lr}$ curve exceeds 30 meters $(2 \mathrm{Lr}>30)$, then the nominal moment curve of the beam is limited to 30 meters.

\subsubsection{Composing Table of Section Axial Capacity and Coefficient of $m \& U$}

The value of the coefficients $\mathrm{m}$ and $\mathrm{U}$ is a multiplier coefficient that is used to obtain the equivalent $\mathrm{Pu}$ value for each section that will be used as a beam-column element due to the effect of bending moments. $\mathrm{Pu}$ equivalent is the ultimate axial value which is obtained from the combination of the ultimate axial capacity $P_{u}$, the x-direction bending moment $\left(M_{x}\right)$, and the y-direction bending moment $\left(M_{y}\right)$ values. The equivalent $\mathrm{Pu}$ value is used as a determining value for the factored section axial capacity $\left(\varnothing P_{n}\right)$. A profile will be said to be efficient if the equivalent $P_{u}$ value of the structural element is close to the $P_{n}$ value of the structural element.

The table of the axial capacity of sections and $m \& U$ coefficients will be summarized in tables as the result of the analysis process. Each table will contain the axial capacity of the section, the value of the M coefficient, and 
the value of the $U$ coefficient for each IWF and HCS section.

This table will contain the entire sections that have been analyzed. The table contains the axial capacity, the value of $\mathrm{m}$, and the value of $\mathrm{U}$ from $\mathrm{Lb}=0.5$ meters to 15 meters for each steel grade.

\subsection{Section Data}

The data used in the analysis process are IWF and HCS sections which consist of 81 IWF sections and 19 HCS sections. The IWF sections are used in the analysis of beams, columns, and beam columns while HCS sections are used in the analysis of columns and beam-columns.

\section{Results and Discussions}

\subsection{Bending Moment Capacity Graphs}

Below are the samples of the results of the analysis of the bending moment capacity steel sections as beams

The figures of bending moment capacity for each steel grade above shows that the value of the bending moment capacity in each section increases in proportion to the quality of the steel used. The greater the quality of the steel, the greater the moment capacity. The greater the quality of steel, the crosssection of the profile closer to the limit of compactness.

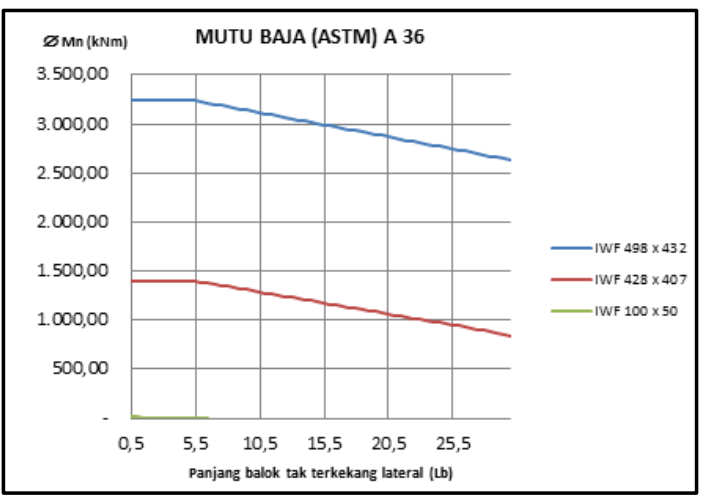

Fig. 1. Factored nominal bending capacity (ØMn) of beams using A36 steel grade

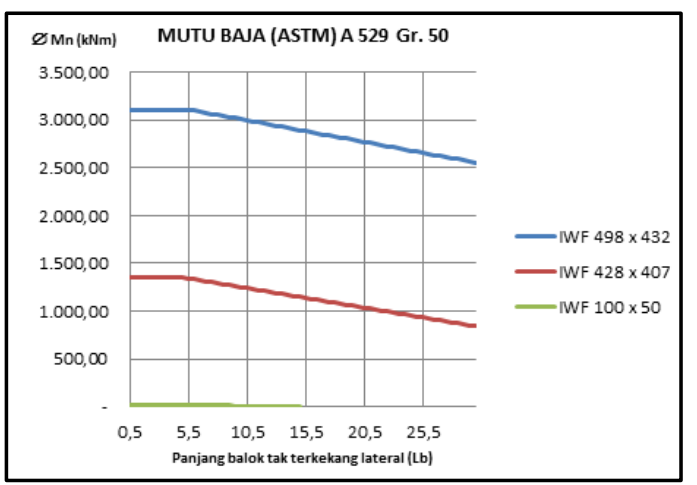

Fig. 2. Factored nominal bending capacity (ØMn) of beams using A529 Gr. 50 steel grade

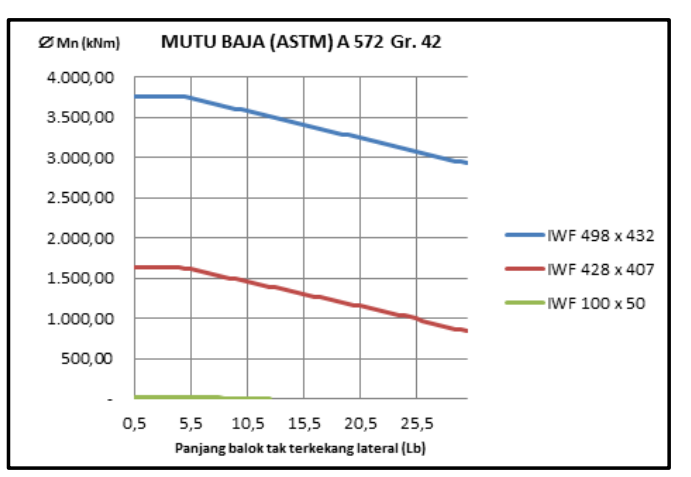

Fig. 3. Factored nominal bending capacity (ØMn) of beams using A572 Gr. 42 steel grade

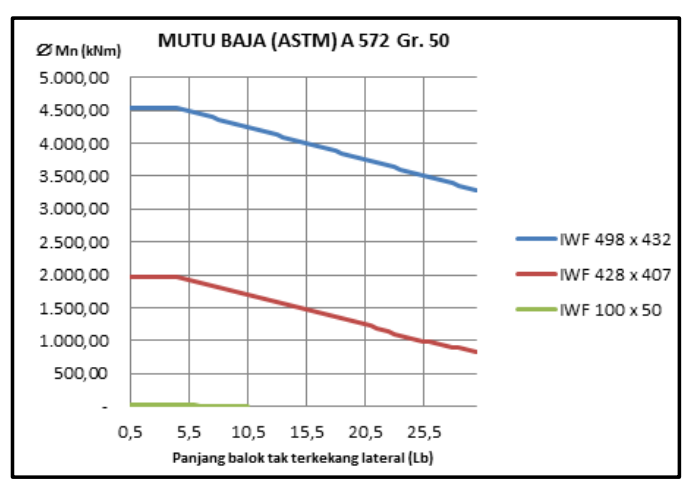

Fig. 4. Factored nominal bending capacity $(\varnothing \mathrm{Mn})$ of beams using A572 Gr. 50 steel grade

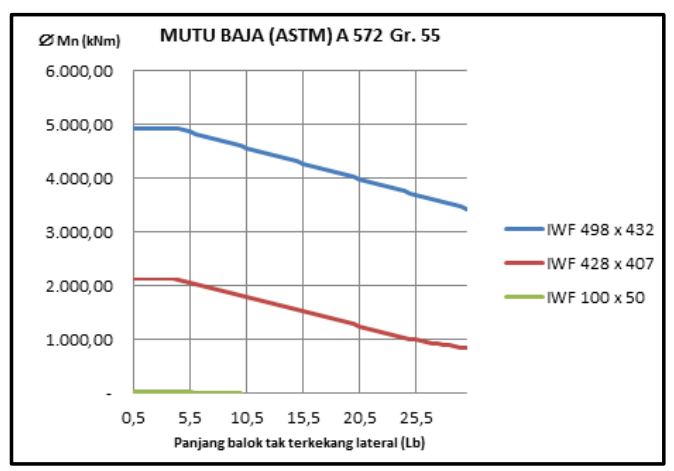

Fig. 5 Factored nominal bending capacity (ØMn) of beams using A572 Gr. 55 steel grade

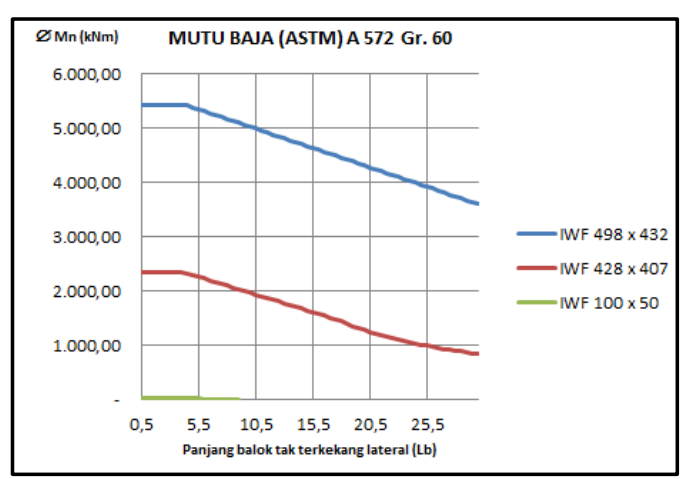

Fig. 6. Factored nominal bending capacity (ØMn) of beams using A572 Gr. 60 steel grade 


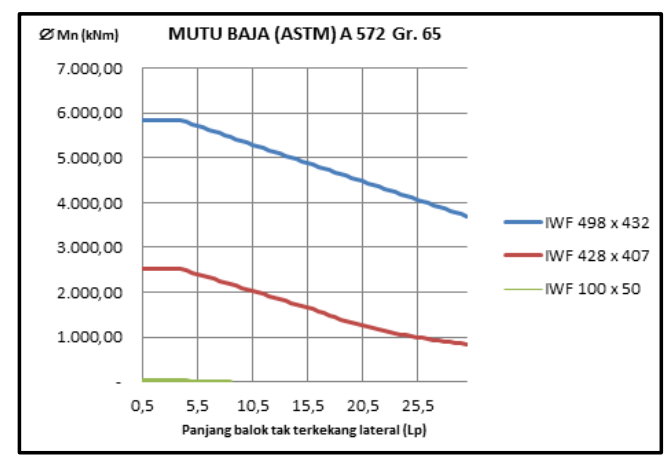

Fig. 7. Factored nominal bending capacity (ØMn) of beams using A572 Gr. 65 steel grade

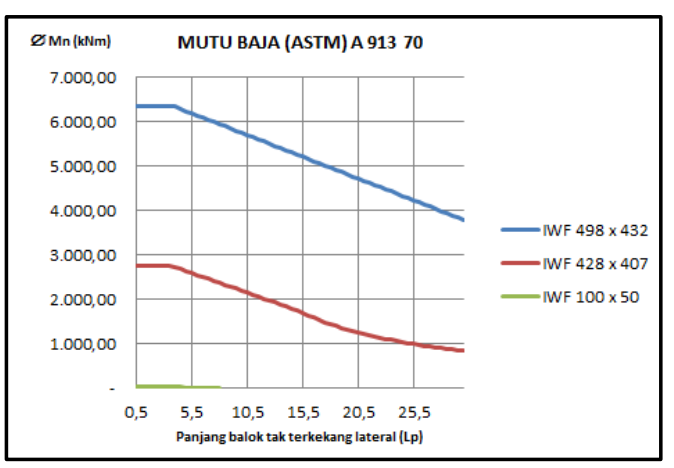

Fig. 8. Factored nominal bending capacity (ØMn) of beams using A913 Gr. 70 steel grade

\subsection{Tables of Factored Axial Capacity, $\mathrm{m} \& \mathrm{U}$ Values}

Table 1. The values of axial capacity, coefficient $m$, and coefficient $\mathrm{U}$

\begin{tabular}{|c|c|c|c|}
\hline \multirow[t]{2}{*}{$\mathbf{k L}$} & PROFIL IWF & $\begin{array}{c}(\mathrm{Pr} / \mathrm{Pc}) \\
\geq 0,2\end{array}$ & $\begin{array}{c}\mathrm{Pr} / \mathrm{Pc}) \\
<0,2\end{array}$ \\
\hline & $\begin{array}{lll}298 & x & 299\end{array}$ & $\mathbf{m}$ & m \\
\hline 0,5 & 2.418 & 7,1 & 15,9 \\
\hline 1 & 2.382 & 7,0 & 15,7 \\
\hline 1,5 & 2.328 & 6,8 & 15,3 \\
\hline 2 & 2.262 & 6,6 & 14,9 \\
\hline 2,5 & 2.190 & 6,4 & 14,4 \\
\hline 3 & 2.118 & 6,2 & 13,9 \\
\hline 3,5 & 2.048 & 6,0 & 13,5 \\
\hline 4 & 1.984 & 5,8 & 13,1 \\
\hline 4,5 & 1.925 & 5,8 & 13,0 \\
\hline 5 & 1.873 & 5,7 & 12,9 \\
\hline 5,5 & 1.827 & 5,7 & 12,9 \\
\hline 6 & 1.746 & 5,6 & 12,6 \\
\hline $\mathrm{U}$ & 2,2 & & \\
\hline Lp & 3,8 & & \\
\hline $\mathrm{Lr}$ & 13,0 & & \\
\hline
\end{tabular}

Axial capacity tables are used to determine efficient profiles for column and beam-column elements. The values of axial capacity, coefficient $m$, and coefficient $\mathrm{U}$ in the table are presented for a compact profile, with a sample of Table 1 .

\subsection{Table Usage Example}

1. Given $\mathrm{Pu}, \mathrm{Mux}, \mathrm{Muy}$ $P_{u}=1100 \mathrm{KN}, M_{u x}=60 \mathrm{KNm}$, and $M_{u y}=22 \mathrm{KNm}$.

2. Determine steel specifications to be used. ASTM-A 36, with $F_{y}=250 \mathrm{MPa}$.

3. Determine effective length factor $(\mathrm{k})$ and beam column element length (L). $\mathrm{k}=1, \mathrm{~L}=5 \mathrm{~m}$

4. Determine initial values of $m$ and $U$

Determined using average of $\mathrm{m}$ and $\mathrm{U}$ values obtained from the tables

$\mathrm{m}=5 \mathrm{~m}^{-1}$

$\mathrm{U}=4$.

5. Calculation of $\mathrm{Pu}$ equivalent $\mathrm{I}$.
$P_{u}$ equivalent I
$=P_{u}+\mathrm{m} \cdot M_{u x}+\mathrm{m} . \mathrm{U} \cdot M_{u y}$
$P_{u}$ equivalent I
$=1.100+5.50+5.4 .22$
$P_{u}$ equivalent $\mathrm{I}=1.840 \mathrm{kN}$

6. Determining IWF section with $\varnothing \quad P_{n}$ value approaching $P_{u}$ equivalent I value using table 2 .

Table 2. IWF section with $\varnothing P_{n}$ value approacing $P_{u}$ equivalent I

\begin{tabular}{|c|c|c|c|}
\hline \multirow{2}{*}{$\mathbf{k L}$} & PROFIL IWF & $\left(\begin{array}{c}\mathbf{P r} / \mathbf{P c}) \geq \\
\mathbf{0 , 2}\end{array}\right.$ & $\begin{array}{c}(\mathbf{P r} / \mathbf{P c})< \\
\mathbf{0 , 2}\end{array}$ \\
\cline { 2 - 4 } & $\mathbf{2 9 8} \mathbf{\mathbf { 2 9 9 }}$ & $\mathbf{m}$ & $\mathbf{m}$ \\
\hline 0,5 & 2.418 & 7,1 & 15,9 \\
\hline 1 & 2.382 & 7,0 & 15,7 \\
\hline 1,5 & 2.328 & 6,8 & 15,3 \\
\hline 2 & 2.262 & 6,6 & 14,9 \\
\hline 2,5 & 2.190 & 6,4 & 14,4 \\
\hline 3 & 2.118 & 6,2 & 13,9 \\
\hline 3,5 & 2.048 & 6,0 & 13,5 \\
\hline 4 & 1.984 & 5,8 & 13,1 \\
\hline 4,5 & 1.925 & 5,8 & 13,0 \\
\hline 5 & 1.873 & 5,7 & 12,9 \\
\hline 5,5 & 1.827 & 5,7 & 12,9 \\
\hline 6 & 1.746 & 5,6 & 12,6 \\
\hline $\mathrm{U}$ & 2,2 & & \\
\hline $\mathrm{Lp}$ & 3,8 & & \\
\hline $\mathrm{Lr}$ & 13,0 & & \\
\hline & & & \\
\hline
\end{tabular}

7. IWF $298 \times 299$ is chosen

8. Calculation of $P_{u}$ equivalent II

$\frac{P_{u}}{\varnothing P_{n}}=\frac{1.100}{1.873}=0,58>0,2$

Nilai $\mathrm{m}$ dan $\mathrm{U}$ are using values obtained from the table of subsequent section:

$\begin{array}{ll}\mathrm{m} & =5,7 \mathrm{~m}^{-1} \\ \mathrm{U} & =2,2\end{array}$

Hence :

$P_{u}$ equivalent II $=P_{u}+\mathrm{m} \cdot M_{u x}+\mathrm{m} . \mathrm{U} \cdot M_{u y}$

$P_{u}$ equivalent II $=1.100+5,7.60+5,7.2,2.22$

$P_{u}$ equivalent II $=1.717 \mathrm{kN}$

9. Determining IWF section with $\varnothing \quad P_{n}$ value approaching $\mathrm{P}_{\mathrm{u}}$ equivalent II 
Table 3. IWF section with $\varnothing \mathrm{P}_{\mathrm{n}}$ value approaching $\mathrm{P}_{\mathrm{u}}$ equivalent II

\begin{tabular}{|c|c|c|c|}
\hline \multirow{2}{*}{ kL } & PROFIL IWF & $\begin{array}{c}\mathbf{( P r} / \mathbf{P c}) \\
\mathbf{0 , 2}\end{array}$ & $\begin{array}{c}\mathbf{( P r} / \mathbf{P c}) \\
\mathbf{0} \mathbf{2}\end{array}$ \\
\cline { 2 - 4 } & $\mathbf{2 9 4} \mathbf{x} \mathbf{3 0 2}$ & $\mathbf{m}$ & $\mathbf{m}$ \\
\hline 0,5 & 2.347 & 7,8 & 17,5 \\
\hline 1 & 2.312 & 7,7 & 17,2 \\
\hline 1,5 & 2.258 & 7,5 & 16,8 \\
\hline 2 & 2.192 & 7,3 & 16,3 \\
\hline 2,5 & 2.120 & 7,0 & 15,8 \\
\hline 3 & 2.047 & 6,8 & 15,3 \\
\hline 3,5 & 1.976 & 6,5 & 14,7 \\
\hline 4 & 1.910 & 6,3 & 14,2 \\
\hline 4,5 & 1.850 & 6,1 & 13,8 \\
\hline 5 & 1.797 & 6,1 & 13,7 \\
\hline 5,5 & 1.739 & 6,0 & 13,5 \\
\hline 6 & 1.641 & 5,8 & 13,1 \\
\hline U & 2,2 & & \\
\hline Lp & 3,6 & & \\
\hline Lr & 9,1 & & \\
\hline
\end{tabular}

10.IWF $294 \times 302$ is chosen

11. Calculating Pu equivalent III

$$
\frac{P_{u}}{\varnothing P_{n}}=\frac{1.100}{1.797}=0,61>0,2
$$

Nilai $\mathrm{m}$ dan $\mathrm{U}$ are using values obtained from the table of subsequent section:

$$
\begin{aligned}
& \mathrm{m} \quad=6,1 \mathrm{~m}^{-1} \\
& \mathrm{U}=2,2 \\
& \text { Hence: } \\
& P_{u} \text { equivalent III }=P_{u}+\mathrm{m} \cdot M_{u x}+\mathrm{m} \cdot \mathrm{U} \cdot M_{u y} \\
& P_{u} \text { equivalent III }=1.100+6,1.60+6,1 \cdot 2,2 \cdot 22 \\
& P_{u} \text { equivalent III }=1.761 \mathrm{kN}
\end{aligned}
$$

12.Determining IWF section with $\varnothing \quad$ Pn value approaching $\mathrm{Pu}$ equivalent III

13.IWF $294 \times 302$ is chosen (equal to previous trial)

14.IWF 294 X 302 is used

\subsection{Testing the Efficiency of Profiles as Beam- column Elements}

The efficiency of the IWF steel section as a beamcolumn element can be tested with the interaction formula of compression and flexural equations based on SNI 1729:2015 article (H1-1a) and article (H1-1b) according to equation 2.33 and equation 2.34: a. for : $\frac{P_{r}}{P_{c}} \geq 0,2$

$$
\frac{P_{r}}{P_{c}}+\frac{8}{9}\left(\frac{M_{r x}}{M_{c x}}+\frac{M_{r y}}{M_{c y}}\right) \leq 1,0
$$

b. for : $\frac{P_{r}}{P_{c}}<0,2$

$$
\frac{P_{r}}{2 P_{c}}+\left(\frac{M_{c x}}{M_{r x}}+\frac{M_{c y}}{M_{r y}}\right) \leq 1,0
$$

Particularly for the example,

$\frac{P_{r}}{P_{c}}=\frac{1.100}{1.797}=0,61>0,2$ hence interaction formula for beam column:

$\frac{P_{r}}{P_{c}}+\frac{8}{9}\left(\frac{M_{r x}}{M_{c x}}+\frac{M_{r y}}{M_{c y}}\right) \leq 1,0$

$\frac{1100}{1797}+\frac{8}{9}\left(\frac{60}{268,320}+\frac{22}{123,210}\right) \leq 1,0$

$0,96 \leq 1,0 \ldots(\mathrm{OK})$.

The interaction coefficient is very close to 1 , hence the steel section obtained is efficient.

\section{Conclusions}

1. The resulting factored nominal moment capacity graphs $\left(\varnothing M_{n}\right)$ can be used as a reference in the process of designing efficient beam elements.

2. The table of factored axial capacity $\left(\varnothing P_{n}\right)$ and the resulting $\mathrm{m}$ and $\mathrm{U}$ coefficient can be used as a reference in the design process of beam-column elements to obtain efficient sections and reduce the iteration process.

\section{References}

1. A. Setiawan, Steel Structure Design with LRFD Method, Erlangga, Jakarta (2008)

2. R. Gunawan, Steel Construction Profile Table, Yogyakarta (1987)

3. SNI 1729:2015, Specifications For Structural Steel Buildings BSN, Jakarta (2015)

4. W. Dewobroto, Behavioral Steel Structures, Analysis \& Design - AISC 2010 2nd Edition (Department of Civil Engineering UPH, Tangerang 2016) 